\title{
On Mobile Learning of College English Based on Smart Phone
}

\author{
Wenjing Sun \\ Zaozhuang University, Zaozhuang, Shandong \\ Email: jingnuoshui@163.com
}

\begin{abstract}
With the rapid development of mobile communication technology and the significant improvement of the functions of smart phone, the rich and diverse learning resources provide convenience for college students to realize mobile learning, which is particularly evident among college students who using smart phones for english learning. College students can learn English through mobile phone whenever and wherever possible based on actual needs, get rid of the bondage of time and space, and adapt to the accelerated modern life. This paper, from the perspective of mobile learning, discusses the advantages and disadvantages of mobile learning of college english based on smart phone with the combination of the characteristics of smart phone, and finally provides some suggestions for college students in using smart phone for mobile learning in their daily life, which is of some enlightenment to English educators and learners.
\end{abstract}

Keywords—Smart phone; Mobile learning; College English

\section{INTRODUCTION}

With the spread of smart phone, there are many bad phenomena in classroom teaching. The students' energy is difficult to concentrate. They placed mobile phone next to their textbook. From time to time, they want to take a glance at it when teacher does not pay attention to them. They look at WeChat, play games, and sometimes even invest in it, forgetting that they are in the classroom of learning. These students' behavior has greatly affected the normal classroom order. Some teachers could not stand it, and then broke the student's mobile phone, which affecting the harmony between teachers and students, and classroom atmosphere is full of gunpowder. There is no shortage of students on campus who are obsessed with cell phones, hitting trees, stepping in puddles, and so on. Because of the emergence of smart phones, teachers and students have contradictions and disharmony, and classroom teaching can not proceed normally. It is imperative to find a solution to the problem and find a good way out for classroom teaching.

\section{DEFINITION AND FEATURES OF SMART PHONE}

\section{A. Definition of Smart phone}

Smart phone is the collective terms for mobile phones that have stronger computing power and functions than traditional mobile phones. In Baidu Encyclopedia, the definition of smart phone is: "Smart phone refers to a program that has a separate operating system like a personal computer. It can be provided by a user to install software, games, and other third-party service providers. The function of the phone is continuously expanded. And you can use mobile communication networks to realize the general name of such a type of mobile phone that is connected to wireless networks."[1] Smart phone today is like a compact version of a PC.

\section{B. Features of Smart phone}

In addition to the full capabilities of ordinary mobile phones, smart phone also has the following five major features:

Firstly, smart phone has the function of wireless access to the Internet. That is, CDMA $1 \mathrm{X}$ or $3 \mathrm{G}$ (WCDMA, cdma-evdo, TD-scdma) networks that need to support GPRS or CDMA networks under GSM networks, and even 4G (HSPA +, FDDLTE, TDD-LTE).

Secondly, function of a PDA. Including PIM (personal information management), schedule notes, task scheduling, multimedia applications, browsing web pages.

Thirdly, an open operating system. With a separate core processor (CPU) and memory, more applications can be installed so that the smart phone' capabilities can be infinitely expanded.

Fourthly, humanized everywhere. Machine functions can be expanded according to individual needs. According to personal needs, real-time expansion of the built-in functions of the machine, as well as software upgrades, intelligent recognition software compatibility, the realization of software market synchronization human features.

Fifthly, the function is powerful. The expansion performance is strong, the third party software supports more. 


\section{The AdVANTAGES AND DEFICIENCIES OF MOBILE LEARNING BASED ON SMART PHONE}

\section{A. The Advantages of Mobile Learning}

With the improvement of the penetration rate of smart phones among college students and the improvement and optimization of efficient network facilities, mobile learning based on smart phones has its unique advantages among college students.

1) Rich in resources. Students learn English by paying attention to the public number, such as "University English", "Teacher Xiaofang", "Higher Education Community Foreign Language Learning", "NECCS", "English Bus", etc.. These public numbers are updated daily, for example: some of the latest English exam information. Sometimes students will be provided with well-organized college English vocabulary of Band Four and Six for students to review, and sometimes provide some English learning skills such as writing, reading, translation and other real topics for students to practice. There are also some teachers who have provided some listening materials for Band Four: news listening, which is the new type of listening exam and it is the most difficult one for students in Band Four examination. Students can download an APP called "Net ease Cloud Music", and then search the radio "Band Four news listening". Students can follow the listening list to listen every day, and attached to the electronic version of the listening text, there are also some exercises that students can do for themselves at any time. There are many kinds of online micro courses and courses to assist New Vision College English reading, writing and listening courses. The explanations are vivid and detailed.

2) Convenient. Most students with smart phones use wireless Internet services; they are all skilled in using software such as audio, video, and e-books on smart phones. At recess, students often use smart phones to check words and use mobile MP3 software to practice listening, which fully demonstrates that students have the ability to carry out English mobile learning. In addition, college students are faced with the pressure of employment. Most students expect to improve their comprehensive ability through English learning so as to have a strong professional competitiveness after graduation. Use smart phones to learn, regardless of time and space restrictions. Walk on the campus, on the bus, and lie in bed before going to bed...You can learn at any time using debris. This instantaneous conversion of learning and leisure conditions is equivalent to the repeated replacement of labor and leisure in a short period of time. Intangibles improve the efficiency of learning and also have great interest. The great storage features of smart phones, e-books, video images, word dictionaries, etc., like a mobile library and movie theater, ease the burden of heavy paper books and learn easily and freely.

3) Timely and efficient. Smart phones are hand held PCs. In the process of learning, students encounter knowledge of foreign cultures and customs that do not know words, do not understand sentence grammar, and do not understand. In life, do not understand any problems and any difficulties encountered, you can use the mobile web platform for online inquiries. For example, unfamiliar words can be queried by
Baidu with "Baidu Dictionary" or "Youdao Dictionary". The words, meanings, pronunciations, usages, etc. of words are explained in detail. Or through WeChat, QQ and other chat software to teachers, classmates, friends and even people who do not know can be consulted. This kind of communication between people and people and people can quickly find answers and solve problems, which saves time and effort.

4) Personalized. Students can choose their own software according to their own majors, study life plans, study platforms, carry out planned studies, detect gaps, and achieve personalized self-learning.

\section{B. The Deficiencies of Mobile Learning}

Although the mobile learning model based on smart phones has developed rapidly, it still faces certain difficulties. It is manifested in the following aspects:

\section{1) Mobile learning distracts students' attention on} learning and affects their learning efficiency.

Mobile learning is a fragmented learning that uses piecemeal time. The learning environment and learning status are not fixed. In a noisy environment, it is difficult for students to concentrate their learning energy under the changing state of mobile learning. Students should not only consider the content of learning but also consider the safety of their own environment. Although students study in addition to life and entertainment and meet the learning conditions of consciousness memory in psychology, learning efficiency will be greatly affected. In addition, if the network connection is not smooth, the voice in the voice device can not be played normally, and the image is delayed, it will greatly affect the learner's emotions and bring about frustration. The learner subconsciously believes that this system is clumsy and lacks humanistic care. It is an inefficient and unapproachable learning method. Therefore, the learner's attention is distracted, which leads to a feeling of learning fatigue and affects the learning efficiency.

2) Mobile learning based on smart phone limits students' learning content.

Mobile learning is targeted at certain specific groups. Not all groups are suitable for mobile learning. In addition, mobile learning devices have limited screen sizes and limited presentation content. Mobile learning in a fixed state, length of content, concise and complex, can read and write. In mobile learning, learners should choose their own learning content according to their own circumstances. Most of the learning content needs to be streamlined and should not be too long. Today's smart phones are very rich in functions and have a high usage rate. However, the hardware of mobile phones has limitations, making the individual functions more different from computers and using them less professionally in English learning. At the same time, the less self-controlled part of college students may use more of their entertainment features when using smart phones, which instead affects normal learning. The battery life of smart phones is also often criticized. Although the popularity of mobile chargers has eased this problem to some extent, it is difficult to maintain the amount of electricity spent on learning for a long time. In 
addition, the long-term use of smart phones for text reading and video viewing damage to the eyes of students is also a matter of concern.

3) Mobile learning can easily affect students with bad information. Students need to use the Internet to look up resources during the daily learning process of using mobile devices. At the same time, in the web-based mobile environment, there will be a large number of bad information websites. Due to the lack of social experience of student, the variety of online fraud, and the sophistication of the means, most of them are lured by students, lack of identification ability, and weak sense of self-protection. Students are easily deceived, resulting in loss of personal money, misguided.

4) The teachers' information technology level influences the teaching effect. Mobile learning is a new thing. Teachers have not been contacted in the student era, and they have not undergone specialized studies in this area. The limited knowledge of information technology acquired by self-study and participation in some training has led to different levels of information technology for teachers. Teachers in daily teaching, only according to the learning situation of their own students, tailor-made learning resources can more effectively improve students' learning performance, improve learning enthusiasm and thirst for knowledge.

\section{SPECIFIC StRATEGIES OF MOBILE LEARNING BASED ON SMART PHONE}

\section{A. To establish value orientation of mobile learning and guide students to understand the advantages and disadvantages of mobile learning.}

Smart phones are technology products based on Internet technology. They have rich functions and advantages of convenient operation, so they can meet many needs of English teaching. However, smart phones can also bring great disadvantages. Smart phones can easily distract students' attention. And it will have a negative impact on students' eyesight and other physical conditions. In the online environment, in addition to providing learning functions for students, smart phones will also provide a variety of entertainment functions. Software such as games, videos, animations, and social networking are more entertaining, so students can easily distract their attention while studying. The long-term use of smart phones will also form a sense of dependence on mobile phones, which will not only cause students to suffer from insomnia, dizziness and other conditions, but also endanger students' vision. In view of the negative effects of smart phones, we must establish the correct value orientation in English teaching, make students realize the possible disadvantages of mobile learning, and guide students to clearly define the goals and tasks of learning. At the same time, it also needs to rely on the power of technology to design supervised software or functions, so that students can focus on learning content, prevent students from distracting attention, and indulge in mobile entertainment functions, so as to give full play to the advantages and values of mobile phones in English teaching.

\section{B. To enrich mobile learning data resources and fully introduce smart phone application technology.}

Under the impetus of science and technology, smart phone is no longer a simple communication tool, but a mobile device that integrates many functions such as communication, data inquiry, information transmission, voice chat, and entertainment learning. Under the support of network information technology, Smart phone functions can be maximized, and a variety of information resources can be rapidly circulated and transmitted. In the course of English teaching, teachers and students are not only able to start learning and communication, but also be able to immediately consult materials and listen to class training. Of course, the realization of these functions needs to be combined with the needs of students. Different students have different English abilities and students have different hobbies. Therefore, the unified teaching model obviously can not meet the learning needs of students. It is also impossible to conduct individualized guidance and training for students. In order to fully meet the learning needs of students, it is necessary to build a personalized information database for different English modules, and to study the application of English basic knowledge and application skills in mobile phones. Combining the concepts of mobile learning, integrating video, audio, text, animation and other resources, and combining with different stages of teaching, building a personalized curriculum resource base, sharing resources through network technology, and playing the role of network technology connection, Connect mobile terminals to computers and other devices by creating accounts, and provide some download functions to facilitate students 'offline learning. When building the learning resource bank, we should highlight the advantages of mobile devices, divide the whole learning content into several learning sections, and highlight the key knowledge in the form of short and concise, so as to facilitate students to use their spare time to study and supplement.[2]

\section{To establish a diversified mobile learning model to give full play to the convenience of mobile platform.}

As an important communication tool, the learning and application environment of English plays an important role in learning effect. The learning process of students under the current English teaching mode should be limited by the teaching place and time, and students 'initiative can not be fully exerted. In order to break through this restriction and reform the current situation of English teaching, the school must establish a diversified mobile learning model and make full use of different learning resources, such as video teaching, story teaching, scene teaching, etc.. Combining students' learning needs with specific learning stages, we should build a systematic mobile learning model. In particular, we should make full use of various English learning software of smart phones and strengthen cooperation between schools and software design companies. The combination of teaching needs and resource design makes the advantages of smart phones come into full play. 
D. To Strengthen professional assistant guidance and establish mobile learning evaluation mechanism.

The use of smart phone for English learning requires students to have strong self-control ability. In the process of developing students' self-control ability, the cultivation of students' self-learning consciousness will have a positive effect on the learning effect. In response to this problem, schools can seek the assistance of professionals for guidance. Prior to mobile learning, professionals can organize specialized courses to train students in learning methods and processes, help students to quickly master resource search techniques, and be able to communicate and communicate through social software, among others. In addition, the learning process needs professionals to be able to help students solve problems in the application through high-quality services, but also to establish specific channels to help on-the-job personnel understand and master mobile learning methods.

\section{CONCLUSION}

With the improvement of material living standards, people's demand for universal education and lifelong education continues to rise [3]. Mobile learning is an inevitable trend. Through the investigation of college students using smart phones for mobile learning, it can be seen that college students have widely used mobile phones for mobile learning, but their use efficiency is not yet high. Mobile learning based on smart phones still has a lot of room for development among college students. With the gradual maturity of mobile learning theory research, the improvement of hand held devices and $3 \mathrm{G}$ technologies, and the rapid development of modern science and technology and communication technologies. The convenience and flexibility of mobile learning based on smart phone will have a profound influence on the educational practice in the future. For college students, we should make full use of the advantages brought by smart phone to college students at this stage, and make good use of it. We believe that with the development of technology and the innovation of mobile communication technology, the performance of smart phone will be gradually improved. Meanwhile, with the improvement of mobile learning needs, the continuous attempt and research on mobile learning will bring a wide future for mobile learning of smart phone.

\section{REFERENCES}

[1] Baidu Encyclopedia. Smartphone [EB/OL]. $2012-08$ - 16. http:/ /baike. baidu. com/view/535. htm.

[2] Xing Fu, "Mobile Learning of College English Based on Smart Phone," J. Language and Literature Journal: Foreign Language Teaching and Education, 2012, 8:148-149.

[3] Xiaohui Chen, Jing Xu, "Challenges of Mobile Learning Based on Mobile Phone," J. Modern Educational Techniques, 2009, 19(10):83-85. 